\title{
DEVELOPMENT OF A BLOCK TRANSFER DEVICE USING NET CHAINS FOR AUTOMATION AND LABOR SAVING
}

\author{
Hitoshi Noguchi \\ Construction and Control Systems Department \\ Port and Airport Research Institute \\ 3-1-1 Nagase, Yokosuka, 239-0826, Japan \\ Emailnnoguchi@pari.go.jp
}

\begin{abstract}
A device for transferring wave-dissipating blocks was developed using net chains to allow for automation and labor saving. The device spreads net chains over a block and then tightens the net chains using a wire rope connected to a crane to lift the block.

A model device was used to conduct a transfer experiment under several visibility conditions. A practical device was produced, and transfer work was done. The results showed that by adjusting work conditions, the working time efficiency under good visibility situations is $3 \mathrm{~min}$./piece and that for poor visibility situations is about 4-6 min./piece. The cost for transferring a block is about $1 / 3$ of the conventional manual method.
\end{abstract}

Keywords: net chain, block, transfer, labor saving

\section{INTRODUCTION}

A great number of wave-dissipating blocks have been installed in harbors and along the shores. Some need to be transferred due to the development of harbors and coastal areas. This is conventionally done by workers or divers using wire ropes.

However, the work area is unstable and this work is dangerous. Therefore, I have developed a block transfer device for removing and transferring these blocks

\section{OUTLINE OF BLOCK TRANSFER DEVICE WITH NET CHAINS}

\subsection{Composition and outline of device}

The structure of the device is shown in Fig.1. A net chain hangs from the support frame. After adjusting the horizontal position of the device over the wave-dissipating block, the device is lowered. The net chain is set over the wave-dissipating block. The deadweight of the surrounding part of the net chain allows it to slide into the small space between the surrounding wave-dissipating blocks. This allows the net chain to entwine around a leg of the wave-dissipating block.

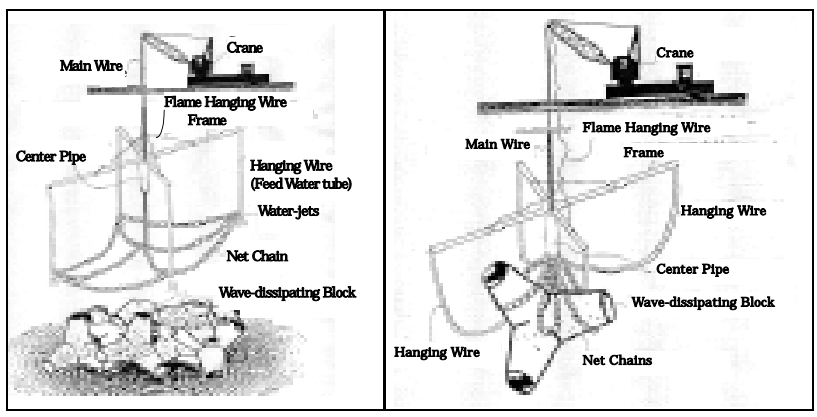

Fig.1, 2 A block transfer device using net chains - before(left) and after(right) lifting -
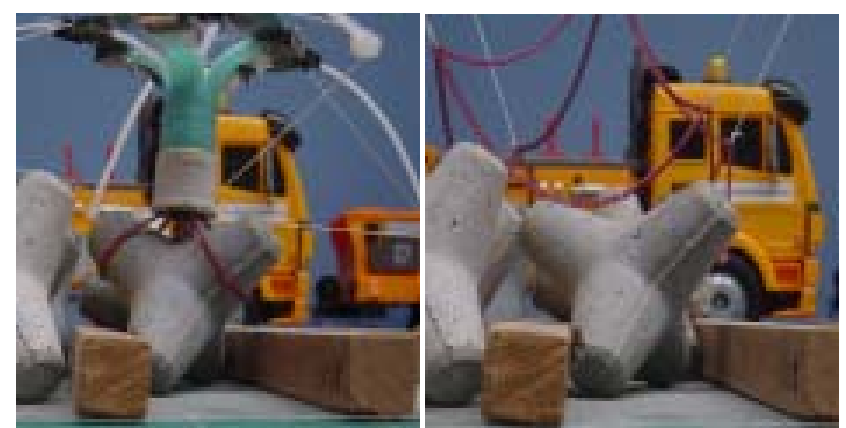

Photo.1 (left) Block unloading on concave part Photo.2 (Right) Wires are loosened, and released block.

When the main wire is rolled up, the net chain is drawn toward the center. This causes the leg of the block to be firmly held, and the block can be lifted (Fig.2).

In the unloading procedure, the lower legs not caught by the net chain are set down on the concave place (Photo.1). The block can be released automatically and easily by simply loosening the main wire of the crane (Photo.2).

For a block buried in sand, high-pressure water gush is used to first remove the surrounding soil, sand and dust (Fig. 1).

\subsection{Principle of block lifting}

(1) With a mesh of net chain

First, let us consider the case in which a block is lifted using a chain.

Without considering the frictional force, to lift up an object, the chain must be rolled around the concave part of the object. The horizontal equivalent sectional area at each height of the 4-leggeds wave-dissipating block is qualitatively shown in Fig.3. The equivalent sectional area refers to the spaces between the legs.

In Fig.3, the distribution shape in the equivalent sectional area shows the central part of the concave section. 


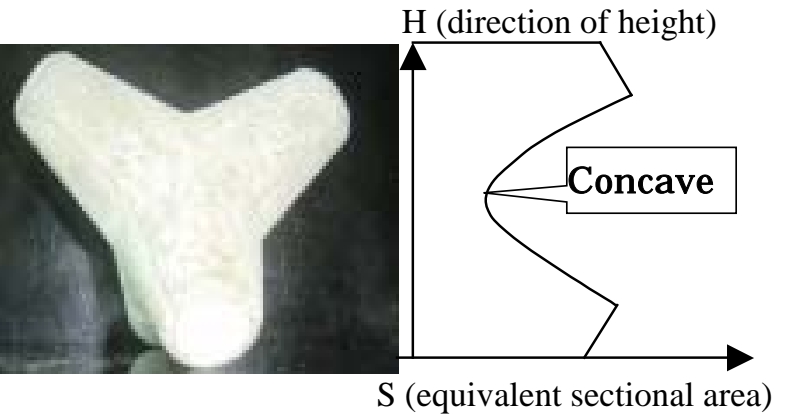

Fig.3 Distribution of equivalent sectional area of block

Therefore, if the chain is horizontally bound to the central part of the block, the lifting can be done without dropping the block. With this device, the lifting up is possible if the mesh of the net chain can become entwined around twolegs of the block.

(2) With two or more mesh portions of the net chain

This development-improved device has more than two portions of net chain mesh to allow lifting up the block even if two legs are separately entwined.

When two portions of the net chain become separately entwined around two legs as shown in Photo.3, the effect is that shown by solid and dotted lines entwining together around two legs. This enables lifting of the block.

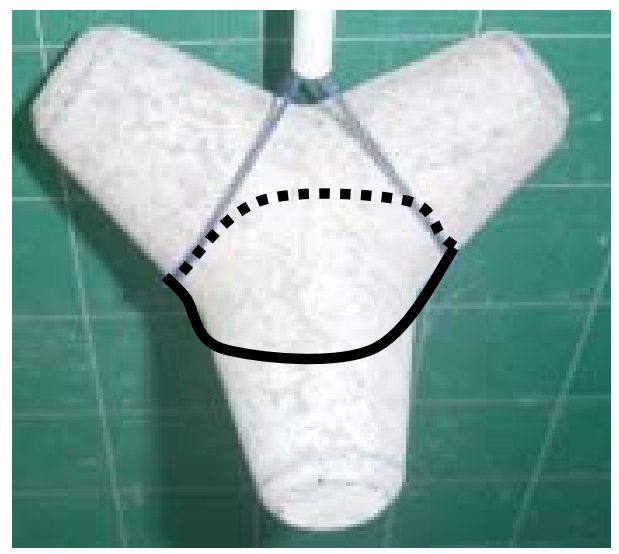

Photo.3 Lifting with two mesh portions

\section{(3) Lifting condition of the block}

As mentioned in (1) and (2), for the lifting of a 4-legged block, the following conditions should be met:

i ) One portion of net chain mesh is entwined around two legs or
ii ) Two portions of net chain mesh are entwined separately around two legs.

\subsection{Device features and advantages}

1) Automation of the work is possible.

2) The structure is simple

3) There are no power parts.

4) The operation is easy.

5) Safety and efficiency are improved.

6) Various shapes can be accommodated.

\section{MODEL BLOCK TRANSFER EXPERIMENT UNDER VARIOUS VISIBILITY CONDITIONS}

Under actual work conditions, the work efficiency differs greatly, according to whether or not the block can be checked visually. The work efficiency does not decrease much if the situation can be checked visually with an underwater camera set up in the hanging frame even for a block in seawater.

However, in some situations, it is not possible to check the block visually with an underwater camera because of low visibility in the seawater. In this case, improvement of the operating method and remodeling the structure of the device ware attempted.

\subsection{Model experiment}

(1) Experimental device (Photo 4)

- Wave-dissipating block model: $6.6 \mathrm{~cm}$ in height, $184 \mathrm{~g}$ in weight (1/32 of the corresponding 6.3 type block)

- Block transfer device: having a chain 1/32 the thickness of the chain of the use load $6.4 \mathrm{t}$.

- Track crane model: Radio control type model.

Using the controller, the boom is turned, expanded and contracted, rising and lowering, and the wire rolls up and down.

- Releasing of the block: The ruggedness was achieved using rectangular lumber. The block is released by simply loosening the chain (Photo 1,2).

- Screen: For the case of muddy water, a screen is installed to prevent direct viewing of the block (Photo 5).
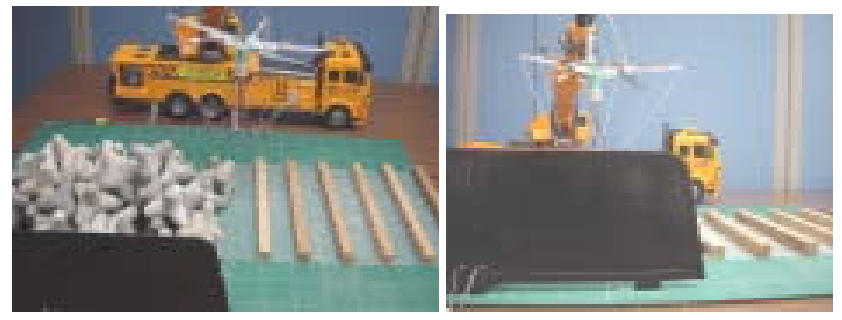

Photo.4 (left) Model block transfer experiment panorama Photo.5 (right) View from the operator

\section{(2) Experimental method}

Transfer of a mountain of wave-dissipating blocks using the controller was done.

Visual checking of the block by the crane operator can greatly raise efficiency.

The following conditions were set for an experimental case.

(1) The operator directly checks the block visually.

(2) The block is checked visually through the camera image set at the crane boom point.

(3) Voice instruction comes from the indicator who can check the block visually.

In muddy water (visibility $0 \mathrm{~m}$ ), two methods were tried without visual checking of the block.

The first method is "(4) a method of searching for the position of the block by moving the transfer device." 
The device is lowered with the net chain expanded (Photo 6 ). When the bottom of the chain comes into contact with the block, the lowering is stopped and the device is moved in the horizontal direction. The stop position is grasped from the movement of the chain on the sea surface. The net chain catches onto the block leg moving in the horizontal direction, and the movement of the device is stopped (Photo 7).

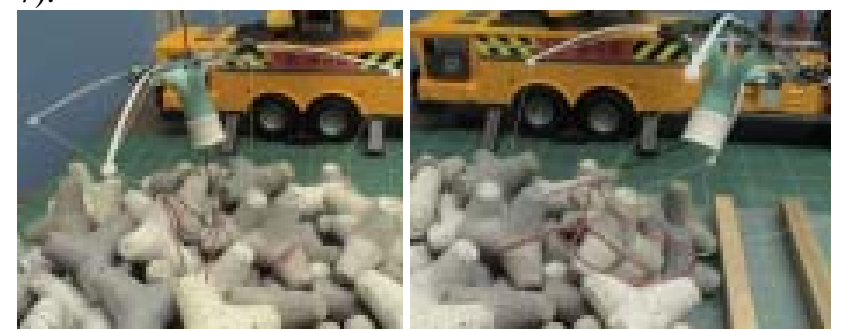

Photo.6 (left) The net chain is lowered.

Photo.7 (right) Catching of block leg by the horizontal movement

The horizontal position of the device is returned to the catching point, then lowered at the position (Photo 8). The net chain is tightened, entwining around the block leg, and the block is lifted (Photo 9).
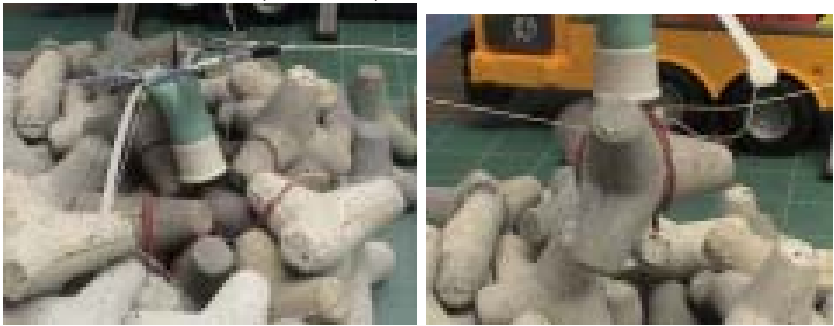

Photo.8 (left) Return to the catching point, and lowered Photo.9 (right) Block lifting

The second method for poor visibility conditions is "(5) Remodeling of the device to increase the area of the net chain about fourfold and the number of mesh sections to eight. " (Photo 10)

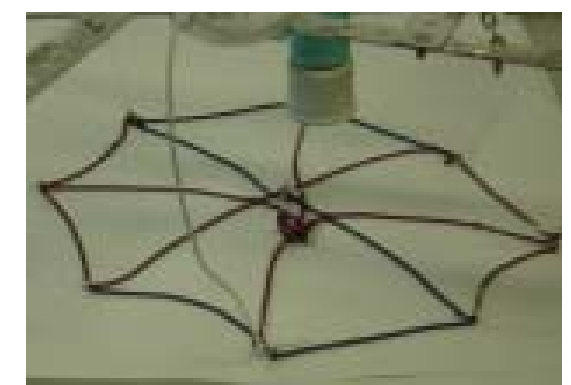

Photo.10 Eight mesh sections chain model

By this remodeling, wherever the device is lowered, one entire block is located under the net chain (Photo 11). The net chain might catch on a nearby block leg, and the target block not be lifted up. In that case, tightening and loosening of the net chain is repeated, until the net chain is removed from the neighboring block leg and can be lifted (Photo 12-14).
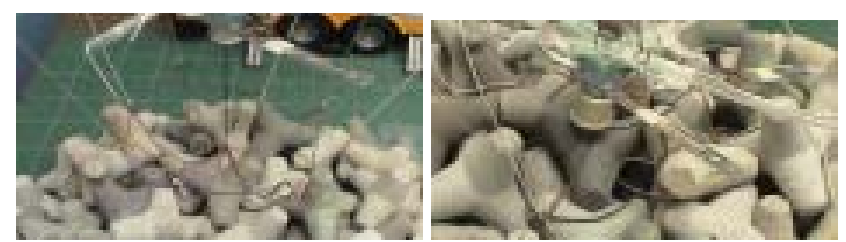

Photo.11 (left) The net chain is lowered.

Photo.12 (right) Repeating of tightening and loosening.

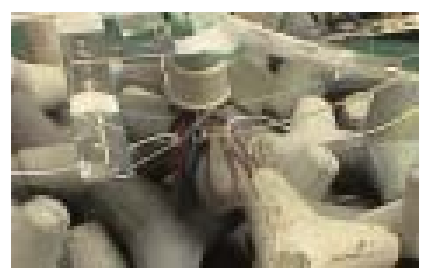

Photo.13 Tightening.

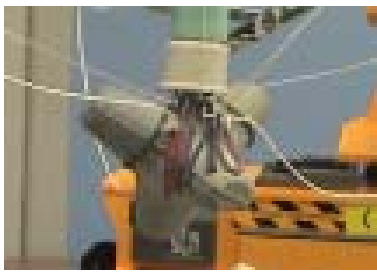

Photo.14 Block lifting
The experimental conditions are presented in Table 1.

Table 1 Block model removal experiment conditions

\begin{tabular}{|c|c|c|c|}
\hline $\begin{array}{l}\text { Assumption } \\
\text { conditions }\end{array}$ & $\begin{array}{l}\text { Experimental } \\
\text { Conditions }\end{array}$ & $\begin{array}{l}\text { Device } \\
\text { form }\end{array}$ & No \\
\hline \multirow{3}{*}{$\begin{array}{l}\text { On surface of the sea } \\
\text { or under sea with } \\
\text { good visibility }\end{array}$} & Direct visual check & \multirow[t]{3}{*}{4 mesh } & (1) \\
\hline & Camera image & & (2) \\
\hline & Voice instruction & & (3) \\
\hline \multirow{2}{*}{$\begin{array}{l}\text { Under muddy water } \\
\text { (visibility } 0 \mathrm{~m} \text { ) }\end{array}$} & \multirow{2}{*}{$\begin{array}{l}\text { Blocks are covered } \\
\text { with the screen. }\end{array}$} & 4 mesh & (4) \\
\hline & & 8 mesh & (5) \\
\hline
\end{tabular}

(3) Experimental results

The bar chart of Fig. 4 shows the average time required for block model transfer in each experimental case.

For experiments in which the block could be checked visually, the result of "(1) direct visual check: $75 \mathrm{sec} . /$ piece" and "(2) the camera visual check: $73 \mathrm{sec} . /$ piece" were almost the same. "(3) Voice instruction: $94 \mathrm{sec} . /$ piece" required about $20 \mathrm{sec}$. more than "(1) direct visual check".

When the block could not be checked visually," (4) Improving Operation" was $145 \mathrm{sec} . /$ piece, and“ (5) Improving Device" was $93 \mathrm{sec}$. These procedures required $70 \mathrm{sec}$. and $18 \mathrm{sec}$. more than the direct visual check (1) of $75 \mathrm{sec}$.

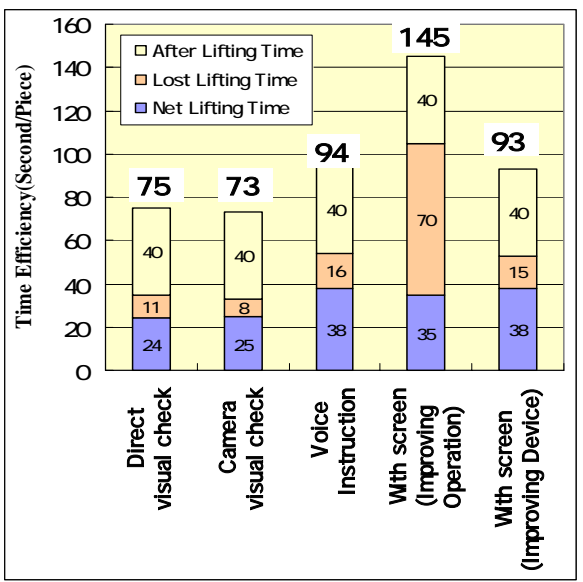

Fig.4 Block model transfer average time required 
Next, let me explain the breakdown in each graph.

Opening the net chain above the block was defined as the starting time. The time required for lifting was from this starting time until completion of the procedure.

The time from the completion of the lifting until the return to the position above the block was the "Time required after the lifting procedure." This time after the lifting procedure was similar in most cases, and the time efficiency was also the same. The work after the lifting procedure was recorded on video and analyzed. The time required averaged 40 seconds, being similar for all cases with no significant difference. Therefore, for all cases, the "Time required after the lifting" was assumed to be $40 \mathrm{sec}$.

The "Time required after the lifting" was subtracted from the "Transfer time required" and calculated as the "Lifting time required" in each experiment case. The lifting time required becomes longer if failures are repeated. The time for lifting without the failure was defined as the "Net lifting time" in each case. Subtracting the "Net lifting time" from the "Lifting time required" was assumed to be the "Lost lifting time".

These breakdowns analyzed for each case are shown as a graph in Figure 4.

In "(2) the camera image" case, there was little failure and the lost lifting time was minimized because the entwining of the net chain to the block leg could be checked visually. On the other hand, in "(4) Visibility-improving operation", the lifting failure often occurred and the lost lifting time was great because of poor visibility.

\subsection{Water tank model experiment}

(1) Outline of experiment

The water tank experiment of the block-lifting model was done under two situations.

(1) Mountain of blocks loaded in muddy water (visibility 0 $\mathrm{cm}$ )

Using a search method and an eight-section mesh device.

(2) Block and model car buried in sandy bottom

Gushing water from the four corners of the net chain was used to remove the sand around the buried block and model car.

(2) Experiment result

The block could be lifted using the procedure described for case (1) by two methods. (Photo 15 and 16)
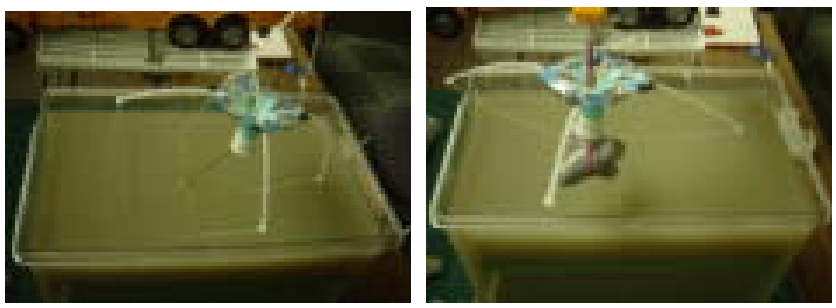

Photo.15, 16 Muddy water experiment

$\{$ Searching (left) and lifting (right) $\}$
In case (2), the block and model car buried in sand could be removed after the gushing water had removed the surrounding sand (Photo 17-21).
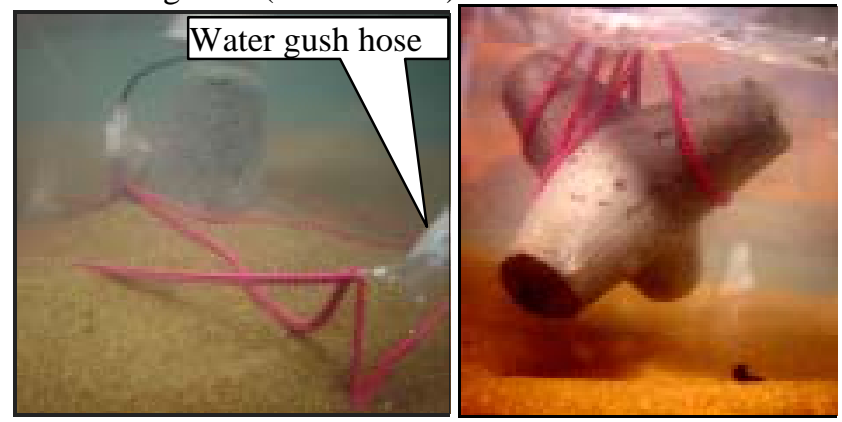

Photo.17 (left) Net chains on the buried block Photo.18 (right) Block lifting
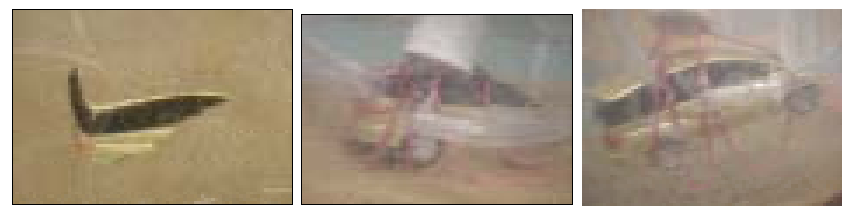

Photo-19, 20,21 Lifting of a model car buried in sand

\section{BLOCK REMOVAL WORK}

This device was used to remove wave-dissipating blocks located at the front of a quay. The blocks to be removed were located on and under the surface of the sea. This device was used together with procedures by workers and divers.

- Location: Front side of shore protection area in Kawashimo Port, Shimane Prefecture

- Date: April 2004

- Type of block: Four-legged wave-dissipating blocks (Mostly $6.3 \mathrm{t}$ type tetrapod and $6 \mathrm{t}$ type shake block)

- Crane used: 100 t hanging crawler crane

\subsection{Block transfer device}

The block transfer device was produced using a chain of $6.4 \mathrm{t}$ use load because the maximum net weight of block was $5.8 \mathrm{t}$ (Photo 22). The size of the hanging frame of about $4 \mathrm{~m}$ is composed of H-frame steel.

\subsection{Removal work procedure}

The block transfer device is hung from a crawler crane. The center parts of the net chain are connected with the main rolling wire. The hanging frames are connected with the sub-rolling wire. The crane is located on the quay.

The wave-dissipating blocks are lifted one by one and temporarily placed on the ground within range of the reach of the crane boom. The wave-dissipating block can not be seen from the crane driver's seat because visibility is blocked by the shore protection wall. Therefore, the indicator views the work situation and sends instructions to the crane driver via a wireless system (Photo 23). 


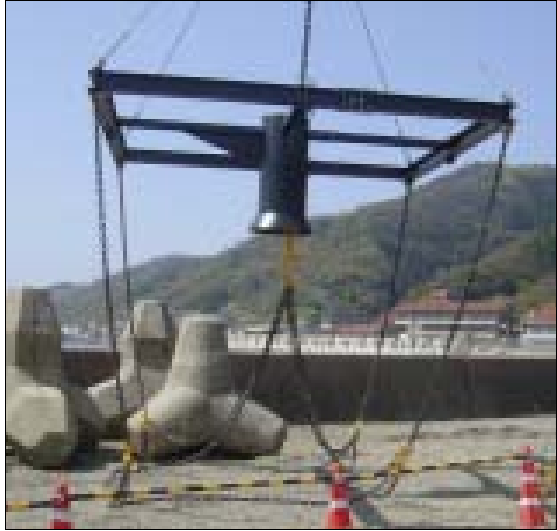

Photo.22 Block transfer device

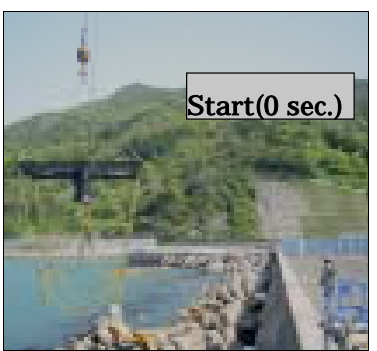

Photo.23 Work starting

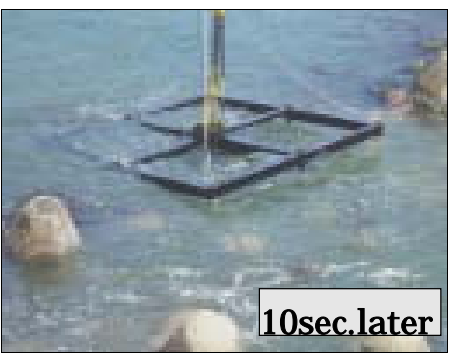

Photo.24 Lowering

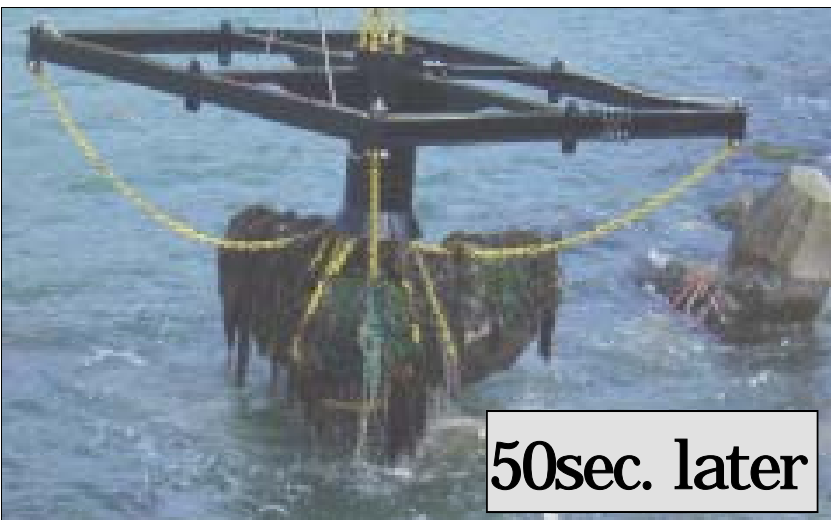

Photo.25 Lifting (1)

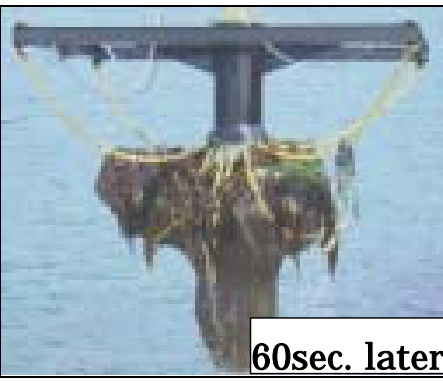

Photo.26 Lifting (2)

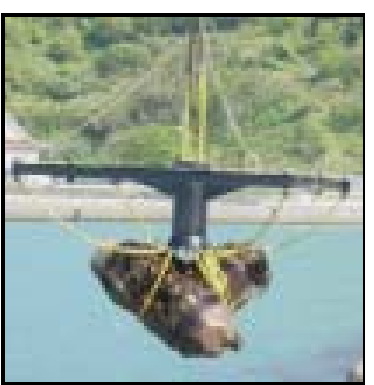

Photo.27 Broken block
For a block under the sea, the indicator on the quay visually checks the approximate position of the block (Photo 24, 25, 26).

For a block located deep in the sea with no possibility of visual checking from the quay, the work is directed by a diver. Workers supported the release procedure of the net chain from the block on flat ground at this site.

\subsection{Work result}

The net chain could be used throughout the entire process as no damage was incurred.

The work results of three work situations are presented in Table 2 to allow comparison of the work situation by worker and diver using the wire multiplication method.

Table 2 Block removal work result

\begin{tabular}{|c|c|c|c|c|}
\hline Bl ock Si tuation & The devi ce & lifting & Wbrkers anc & $\begin{array}{l}\text { d Di vers } \\
\text { lifting }\end{array}$ \\
\hline On surface of the sea & $\begin{array}{l}\text { The 1st day } \\
8.0 \mathrm{~min} / \text { piece } \\
\text { (30pieces for } 4.0 \mathrm{~h} . \text { ) } \\
\text { The } 2 \mathrm{nd} \text { day } \\
6.7 \mathrm{~min} / \text { piece } \\
\text { (67pieces for } 7.5 \mathrm{~h} . \text { ) }\end{array}$ & \multirow[t]{3}{*}{$\begin{array}{l}\text { aut omat i } \\
\text { cal I y }\end{array}$} & $4.3 \mathrm{~min} / \mathrm{piece}$ & $\begin{array}{l}2 \\
\text { wor ker s }\end{array}$ \\
\hline $\begin{array}{l}\text { Under surface of the sea } \\
\text { (Check vi sual I y) }\end{array}$ & $\begin{array}{l}5.0 \mathrm{~min} / \mathrm{piece} \\
(12 \text { pieces for } 1 \mathrm{~h} .)\end{array}$ & & 6.1min/piec & 2divers \\
\hline $\begin{array}{l}\text { Under surface of the sea } \\
\text { ( Not check vi sual I y) }\end{array}$ & $\begin{array}{l}\text { 7.0min/pieces } \\
\text { (30pieces for } 3.5 \mathrm{~h} . \text { ) }\end{array}$ & & $6.0 \mathrm{~min} / \mathrm{piece}$ & 2 divers \\
\hline
\end{tabular}

\section{CALCULATION OF TIME AND COST EFFICIENCY UNDER VARIOUS WORKING CONDITIONS}

In this work, the block-releasing work was assisted by workers, and the crane was operated by wireless system instruction from an indicator. These workers were using the device for the first time. Therefore, working time efficiency and cost were calculated on a trial based on the block removal work data considering the data from a model experiment under the hypothesized conditions.

\subsection{Calculation of working time efficiency}

The work conditions of block removal with this device from under the surface of the sea with visual checking are set as situation (1).

In situation (1), it is assumed that situation (2) holds with a camera for visual checking installed at the boom point of the crane or the hanging frame. The crane driver conducts operations referring to this image. In situation (2), the lifting time is calculated to be $21 \mathrm{sec}$ shorter than that for situation (1) from the model experimental data.

In situation (2), it is assumed that situation (3)holds with the block will be released on concaved ground. In situation (3), the block can be released without the assistance of workers. The time required after the lifting is shortened to $96 \mathrm{sec}$. from $170 \mathrm{sec}$. in situation (3) based on the model experimental data.

In addition, in situation (3), a crane operator accustomed to this device is hypothesized as situation (4). Better operator skills can be expected to shorten the procedure by 30 seconds according to the model experimental data.

In situation (4), it is assumed that situation (5) holds in which the search procedure is conducted without the possibility of visual checking. In situation (4), the working time efficiency is calculated from a trial with "Net lifting time: 84 sec." and "Lost lifting up time: $168 \mathrm{sec} . "$ based on model experimental data. 
In situation (4), it is assumed that situation (6) holds in which an eight-section mesh net chain device is used without visual checking, based on the model experiment. In situation (6), the working time efficiency is similarly calculated from a trial with "Net lifting time: $91 \mathrm{sec} . "$ and "Lost lifting time: 36 sec." based on model experimental data.

These calculation results are shown in Fig. 5 together with "Block transfer time efficiency on surface of the sea by workers: (8)" and "Block transfer time efficiency under the sea by divers: (7)".

For the block transfer work at the surface of the sea, time shortening can be expected even of about $2.9 \mathrm{~min} . /$ piece, although for the worker method, $4.3 \mathrm{~min} . /$ piece was required.

When the block can be checked visually with an underwater camera, time shortening can be expected even at the level of about $2.9 \mathrm{~min} . / \mathrm{piece}$, although for the diver method, $6.1 \mathrm{~min} . /$ piece was required.

If an underwater camera cannot be used, a work efficiency of about 4-6 minutes/piece can be expected.

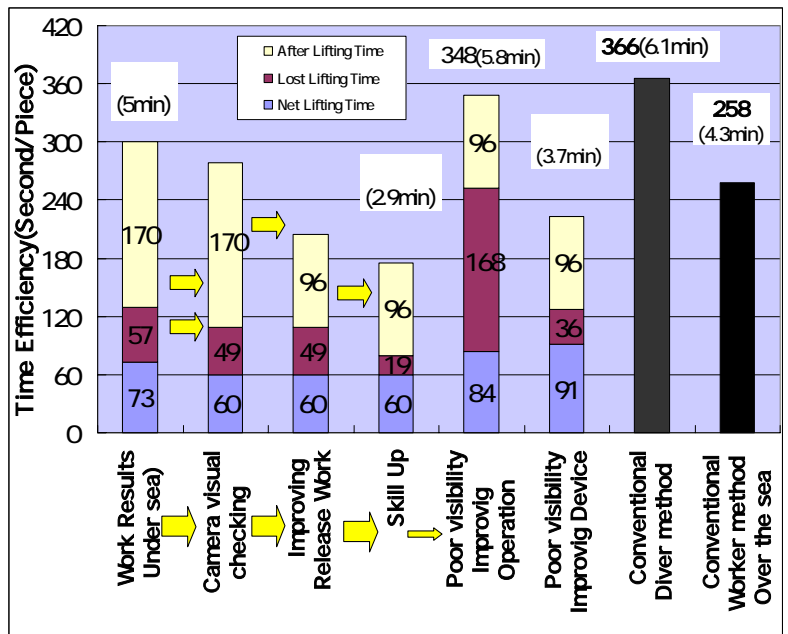

Fig.5 The transfer time calculation in various conditions

\subsection{Calculation of work cost}

The standard work cost per day (eight hours) in situation (4)(6)(8) is shown in Fig.6 . In the situation (4)6, the cost of the worker and the diver decreases greatly.

The graph of the transfer costs of a block is shown in Fig. 7 based on the working time efficiency and the work cost.

Under visual checking situations, the cost can be reduced to about $1 / 3$ by using this device.

Under situations where visual checking is not possible, the cost can be similarly reduced to about $1 / 3 \sim 1 / 4$ by using this device

\section{CONCLUSION}

The conclusion from this research is as follows.

- In the work of transferring underwater wave-dissipating blocks with visually checking, the working time efficiency of this device was $5 \mathrm{~min} . /$ piece.

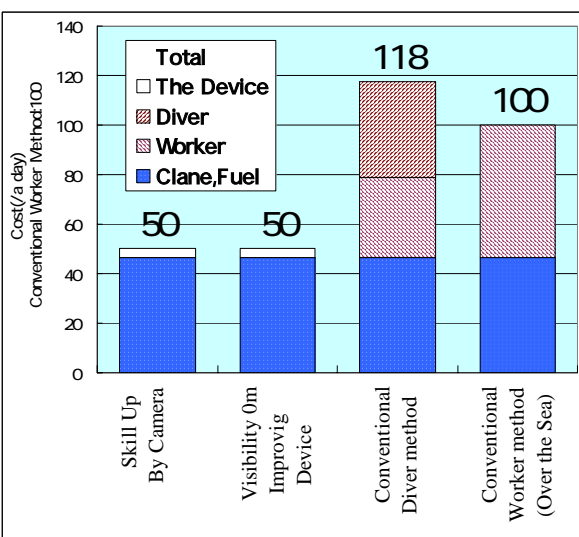

Fig.6 Work cost per a day

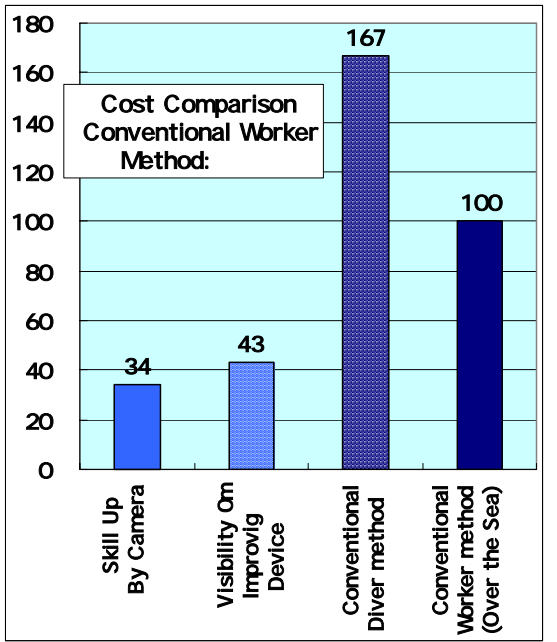

Fig.7 Cost comparison

This exceeded the $6.1 \mathrm{~min} /$ piece of the conventional method executed by divers.

- If the work conditions are established to optimize the operation of this device, the following can be expected.

The working time efficiency becomes about 3-min./piece under visual checking situations, and about 4-6 min./piece when visual checking is not possible.

The removal cost can be reduced to about $1 / 3$ of conventional worker methods.

\section{REFERENCES}

[1] Hitoshi Noguchi, Development of Lightweight Transfer Machine for Blocks Using Net Chains, Technical Note of The port and Airport Research Institute, No.1063, pp1-15, Dec. 2003

[2] Hitoshi Noguchi, Development of Transfer Method of Blocks Using Block Transfer Device with Net Chain to Automate and Save Labor, Technical Note of The port and Airport Research Institute, No.1098, pp1-16, June 2005 